\title{
Notes on Operations
}

\section{Using Verbal Reports to Understand Cataloging Expertise: Two Cases}

\section{Ling Hwey Jeng}

The author discusses the use of verbal reports in protocol analysis to study the quality of cataloging knowledge and skills. The author begins with a discussion of the literature on expertise and on the use of verbal reports and protocol analysis in general, and proceeds to present two examples of the use of verbal reports collected as part of a research project on cataloging expertise. Using findings derived from the verbal reports, the author illustrates the process of hypothesis generation for further research.

\section{W} it take to become one? How do they gain their expertise in cataloging? What is the best way to transfer their knowledge to beginning catalogers so that beginning catalogers can be better trained in a shorter time? In this age of artificial intelligence and expert systems, what knowledge and heuristics should a cataloging system possess to perform like an intelligent human cataloger? These questions focus on two quality-related terms commonly heard among catalogers: professional and expert. Although not universally agreed upon, the term expert in cataloging is usually used to describe a cataloger possessing some combination of experience, knowledge of a special type of material, special language skill, and affiliation with a prestigious library institution. Conventional wisdom such as this helps only to distinguish noncatalogers from catalogers at a very superficial level; it is not meaningful in answering the above questions at any specific level. Although the potential for expert system applications in cataloging has long been recognized (Ercegovac 1984), the recent development of cataloging expert systems (e.g., Davies and James 1984; Hjerppe, et al. 1985; Ercegovac and Borko 1992) provides little practicality beyond prototyping and demonstration (Fenly 1990). The major obstacle to the success of expert

LING HwEY JENG is Associate Professor, School of Library and Information Science, University of Kentucky, Lexington (lhjeng00@ukcc.uky.edu). The author acknowledges the generous support of the Library of Congress during her research residency, with special thanks to Glen Zimmerman, Sarah Thomas, and Tom Yee. Manuscript received March 25, 1996; accepted for publication July 9, 1996. 
systems for cataloging remains in the unknowns of the knowledge base-that is, cataloging expertise (Davies 1992; Hjerppe and Olander 1989; Meador and Wittig 1991; Jeng 1992; Abrera and Shaw 1992; Jeng and Weiss 1994). This paper describes the use of protocol analysis and its resulting verbal reports to study the general strategies, mental models, and problem-solving methods among expert catalogers.

\section{EXPERTISE}

To understand what experts do in cataloging, it is necessary to begin with an understanding of what expertise is in the context of a profession. The Random House Dictionary defines expertise as "a high degree of skills, dexterity or knowledge of a specific subject area." Johnson et al. (1988) say that expertise is a kind of operational knowledge, "characterized by generativity, or the ability to act in new situations, or the capacity to achieve problem solutions." In problem solving such as that found in most professional tasks, expertise is basically a set of requirements that must be satisfied in order to solve problems in a given domain. Literature shows that experts behave differently from nonexperts. La-
France (1989) describes the characteristics of experts' behaviors and how they differ from those of novices. He divides the characteristics into three areas: general knowledge, problem-solving skills, and memory structure (see table 1).

It is believed that experts recognize more complexity and can attend to multiple cues at one time. Furthermore, they know that the importance of some features is contingent on whether or not other features are also present (Johnson et al. 1981). Experts not only know how to recognize the relevant elements in their problem domains but also know how the elements interact and vary with context.

The approaches to problem solving used by experts and novices are different. Studies show that expert chess players recall move sequences in terms of attack and defense strategies (i.e., schema-driven), whereas novices recall them in terms of spacial position (i.e., data-driven). Experts often conduct qualitative analyses of problems and categorize the problems into recognizable types; novices link specific features of problems with specific solutions. Experts focus more on overall goals, while novices focus more on effects. For example, observations suggest that expert basketball players focus on their goal or plan rather than specific events or event sequences. Novices have limited

\section{TABLE 1}

LaFrance's COMparison of EXPERT AND NOVICE KNOWLEdge Characteristics

\begin{tabular}{lll}
\hline & Expert & Novice \\
\hline $\begin{array}{l}\text { Knowledge } \\
\text { Quantity }\end{array}$ & more & less \\
Quality & complex & simple \\
Problem solving & & \\
Approach & schema-driven & data-driven \\
Analysis & problems & solution \\
Focus & goals & effects \\
Speed & automatic & conscious \\
Memory & & \\
Structure & clustered & local position \\
Organization & high level & surface features \\
Experience & episodic & semantic \\
\hline
\end{tabular}


ability to generate inferences and relations that are not explicitly provided.

Speed is another characteristic that distinguishes experts from novices in problem solving. Expert bridge players are like robots. They have great difficulty adapting to the game when changes are made in the rules, especially when the changes are extensive. Novices' performance is less drastically affected by rule changes. Experts' knowledge structures are so committed to memory and so attached to particular strategies that disrupting them causes their entire problemsolving process to be thrown into disarray.

Experts tend to organize their memories by looking for meaningful relations among smaller units and grouping them into larger chucks (Charness 1976; Chase and Simon 1973). In a study of architectural expertise, Akin (1980) found that expert architects recall building plans at several levels, beginning with local patterns (wall segments and doors); then rooms, then clusters of rooms. Experts also rely on a higher level of abstraction in their memory organization. For example, when asked to replicate drawings, expert electronic technicians do so according to the functional nature of the components of a circuit, such as amplifiers, rectifiers, and filters. Novice technicians however, produce copies based more on the spatial proximity of the presented elements (Egan and Schwartz 1979).

The quality of memorized experience is also different between experts and novices. Novices tend to form semantic memory, which is the knowledge of facts, hierarchically arranged. Experts, on the other hand, have good episodic memory, i.e., the knowledge of situations constructed from experience. Episodic memory records and organizes events such that domain concepts are related to each other according to their concurrence in the same episode. Experts are also able to organize individual episodes into generalized abstract situations in their memory (Kolodner 1983).

While LaFrance addresses the differences between experts and novices in general, authors of other studies attempt to address the process of acquiring expertise in particular subject areas. Benner (1984), for example, devotes several chapters to a discussion of various levels of knowledge from novice to expert and how a novice becomes an expert in clinical nursing. She identifies five levels of expertise in nursing:

Stage 1 is called the Novice level. At this stage, nurses are taught about situations in terms of objective attributes and features of their task world that can be recognized without situational experience, as well as context-free rules to guide action with respect to different attributes. The rule-governed behaviors of novice nurses are extremely limited and inflexible. They have little understanding of the contextual meaning of textbook terms.

At stage 2, the Advanced Beginner level, the nurses demonstrate marginally acceptable performance. Having coped with enough real situations, they are now able to note the recurring meaningful situational components, also called aspects of the situation.

Nurses are said to have acquired the knowledge of stage 3 , the Competent level, typically after they have been on the job in similar situations for 2 to 3 years. They begin to see actions in terms of longrange goals and perspectives, and are able to plan their action or solution based on considerable conscious, abstract, analytic contemplation of the problem. Although at this stage the nurses still lack the speed and flexibility of experts, they do have a feeling of mastery and the ability to cope with contingencies of clinical nursing.

At stage 4, the Proficient level, nurses are able to perceive situations as wholes in terms of long-term goals rather than as individual aspects. They can recognize when the expected normal picture does not materialize and possess holistic understanding that helps decision making.

When the nurses reach the highest level of knowledge-stage 5, the Expert level-they no longer rely on a single analytic principle (rule, etc.) or their understanding of the situation to actions. They now have an intuitive grasp of each situation and zero in on the accurate region of the problem without wasteful consideration of a large range of unfruitful, alternative diagnoses and solutions. 


\section{KNowledge ACQUisition}

Studies of learning and knowledge acquisition processes abound in cognitive and educational psychology. Knowledge acquisition has also been a topic of interest among researchers in library and information science (LIS) during the past decade. Richardson gives an overview of the techniques for knowledge acquisition appropriate for LIS in his discussion of knowledge-based systems in general reference work (1995). Ercegovac (1992) provides an empirical study of knowledge acquisition specifically applied to the interpretation of authorship of cartographic materials in map cataloging. In her study, she uses three elicitation methods, including one unobtrusive and two obtrusive measures. The obtrusive methods involve a face-to-face open interview and a onepage, paper-and-pencil, forced-format questionnaire. The unobtrusive measure consists of a content analysis of a sample of 499 machine-readable cartographic entries.

Other researchers concentrate their studies on the process of acquiring specific skills. For example, Cooper (1991) discusses user skill acquisition in office information systems during a three-year study designed to evaluate users' abilities to utilize functions and features of an information system. Hoffman (1989) provides a survey of methods used by researchers for eliciting expert knowledge. He places the typical methods of expert knowledge elicitation into three categories: (1) observation of familiar tasks; (2) unstructured, free-flowing interviews; and (3) protocol analysis of special tasks.

\section{VERBAL REPORTS OF Protocol ANALYSIS}

The use of protocol analysis can be traced to the beginning of this century (Erickson and Simon 1985). Protocol analysis is the process of analyzing the work situation (i.e., a protocol) of a subject (whether an expert or a learner) in order to understand the procedures, knowledge, or skills involved. To allow ample time for analysis and to avoid missing spe- cifics in the process, the subject is often asked to perform routine work (such as cataloging a book), in which the work situation is recorded. The protocol can be recorded via audiotape, videotape, or written notes.

Protocol analysis has been used as a method in expertise studies in the areas of instructional design (Rowland 1992), general problem solving (Saiz and Breuleux 1992), and writing (Smagorinsky 1991). Protocol analysis is used not only for understanding humans but also for the knowledge acquisition process in building expert systems. Martin and Redmond (1989) show the potential of automatic knowledge acquisition in diagnostic domains by coding expert protocols into machine-readable form in a diagnostic system. The system uses the expert's knowledge to solve similar problems that occur in the future and also to apply newly learned information to novel but similar cases. Protocol analysis has also been used in studies of LIS (for example, see Belkin and Brooks 1987; Saracevic 1989). Recently Thomas (1993) used a think-aloud protocol in a qualitative study of novice users to study the user interface of ERIC on the Macintosh

Verbal reports are a tool commonly used in protocol analysis. Subjects are asked to verbalize their activities while performing a particular task. The subject may be asked to describe the process as it occurs or to "think aloud" in work situations involving problem solving or decision making. The interviewer remains silent in the background during protocol recording and only speaks out occasionally to prompt the subject for further explanations. The use of verbal reports through think-aloud methods is explained in detail by van Someren et al. (1994), who describe the think-aloud method as a "very direct method to gain insight in the knowledge and methods of human problemsolving." Verbal reports can also provide information about both sophisticated and general mental processes that are difficult to obtain by other research methods. Verbal reports are especially useful, according to van Someren et al., in investigating differences in problem-solving abilities 
among people, differences in difficulty among tasks, effects of instruction, and other factors that have an effect on problem solving.

The use of verbal reports has some limitations. Even within normal work settings, verbal reports are an obtrusive tool for studying learning behaviors. As with other obtrusive research methods, subjects under study using verbal reports are fully aware of research objectives. With the outcome in mind, some subjects may try to please the researchers, although Norris (1990) concludes in his study that the obtrusiveness does not alter subjects' thinking and performance. Verbal reports are used for direct recording of the thinking and reasoning process, and are different from the "secondary elaboration" method often used to study memory recall (Elmes and Bjork 1975).

The use of verbal reports has proved valuable in studies of learning and knowledge acquisition in spite of their limitations. For example, Schael and Dionne (1991) conclude that a subject's lack of familiarity with the technique of protocol analysis does not affect his or her ability to participate in the protocol analysis.

\section{Cataloging Knowledge Base}

Cataloging is the process of creating surrogates for documents and other bibliographic items, which involves two basic functions: description and summarization (Jeng 1993). In the description process, the cataloger describes the physical attributes of the item and determines useful access points to the item. In summarization, the cataloger attempts to summarize the intellectual content of the item by giving it one or more subject headings and by assigning it a classification number to represent the aboutness of the intellectual content and position the item in the conceptual map of the collection.

To fulfill Cutter's objects and to facilitate end-user retrieval (Cutter 1904), the system of surrogates must allow knownitem searching, category searching, and selection among items. Three kinds of knowledge enable catalogers to achieve these objectives: (1) knowledge about the item itself (both bibliographical and subject knowledge), (2) knowledge about users, and (3) knowledge about the desired surrogate as the end product. To ensure end-user searchability and predictability, catalogers must also be aware of another objective in the cataloging process, that is, to maintain the integrity of the system (Malinconico 1974). In order to maintain system integrity, catalogers need two other kinds of knowledge: (4) knowledge about system configuration, and (5) knowledge about how to provide consistency in the process of creating surrogates, i.e., knowledge about tools and rules used for record production and authority control. The objectives of facilitating end-user retrieval and maintaining system integrity represent two very different perspectives in library cataloging; both must be taken into account when mapping the cataloging knowledge base.

The five categories of cataloging knowledge, recognized as basic components of the cataloging knowledge base (Jeng and Weiss 1994), have been dealt with unevenly in studies on cataloging education and training. A cursory examination of cataloging literature suggests a common belief that there are two stages of knowledge acquisition in cataloging: the education the cataloger receives in an LIS program, and experience in the practice of cataloging. It is commonly held that cataloging education is inadequate in shaping cataloging expertise (Avram 1989). There is little evidence in the literature as to what knowledge catalogers acquire in formal schooling and what knowledge they acquire in practice. Fitzgerald (1989), in a case report of cataloging training at Harvard, points out four practical goals for his training program: (a) to bring catalogers "to an appreciation and mastery of the complexity [of bibliographic records] in the most expeditious way while contributing to the accomplishment of the Department's production goals for the year"; (b) to "teach the creation of bibliographic and authority records and file maintenance"; (c) to "develop the habit of research in the cataloger"; and (d) to have students "learn to understand the meaning of rule-governed creativity." 
However, little is said in his paper about what knowledge enables the cataloger to reach these goals. A recent ALA committee document enumerating essential elements of training programs for entry-level professional catalogers places heavy emphasis on system configurations and cataloging rules yet deals very little with other categories of cataloging knowledge (Association for Library Collection and Technical Services ... 1994). A search beyond the area of cataloging education and training reveals a handful of studies on expert performance in subject analysis and indexing. These constitute two groups. The first group concerns the issues of consistency in indexing performance (Markey 1984; Chan 1989; Sievert and Andrews 1991; Giral and Taylor 1993). Most of the studies found significant inconsistencies in assigning indexing terms or subject headings and document the effects of such inconsistencies on information retrieval. None of the studies, however, goes further to investigate the causes of and possible knowledge discrepancies behind the inconsistencies. The other group focuses on the economic aspect of the process, such as time or cost involved in cataloging and indexing (Line 1969; Reynolds 1975; Kautto 1992). For example, according to Kautto, catalogers spend equal amounts of time in analyzing a document and assigning indexing terms to a document.

\section{Data Collection}

In an attempt to study the quality of cataloging expertise and knowledge base, a project was conducted in which the author analyzed the cataloging process and knowledge used by expert catalogers at the Library of Congress (LC). The goal of the project, titled Project Cataloging Expertise, was to identify individual and organizational factors that contribute to the establishment of cataloging expertise. More specifically, the project attempted to answer the following research questions:

- What are the knowledge and qualifications possessed by expert catalogers?
- What are the major tasks involved in cataloging?

- What skills do catalogers exhibit in the process of cataloging?

- What strategies and patterns do expert catalogers use in cataloging?

- What are the specific problems of cataloging training?

\section{Project Activities}

To collect data for the project, the author spent a total of 15 weeks at the Library of Congress under the sponsorship of LC's Visiting Research in Cataloging Program. Activities during the duration of her research residency included:

- a questionnaire survey, which involved the design of a questionnaire and sample selection, the distribution of questionnaires, and follow-up for nonreturns;

- a verbal report exercise, in which volunteers were asked to keep verbal reports of their cataloging cases according to written instructions given by the author;

- verbal protocol recording, in which the author met with selected senior cataloger volunteers during a typical cataloging session in which the catalogers were asked to think aloud as they cataloged and which the author recorded and documented with notes; and

- observation, in which the author participated in an one-on-one training process in order to observe the experts' cataloging environment (see table 2).

Only two methods, the protocol interview and the verbal report exercise, are described here to limit the scope of this paper.

\section{RESEARCH Methodology}

\section{PRotocol INTERVIEW}

Initial interviews were conducted with division heads to gather information and provide orientation. These interviews helped the author plan the protocol analysis in two phases: protocol interviews and 
TABLE 2

ACTivities of Project

Cataloging EXPERTISE

\begin{tabular}{ll}
\hline Weeks 1-7 & $\begin{array}{c}\text { Questionnaire } \\
\text { Survey } \\
\text { Verbal Report } \\
\text { Weeks 5-11 }\end{array}$ \\
& $\begin{array}{c}\text { Verbal Protocol } \\
\text { Recording }\end{array}$ \\
Weeks 9-15 & Observation \\
Weeks 7-15 & \\
\hline
\end{tabular}

a verbal report exercise. For the protocol interviews, expert catalogers with professional job rankings were invited to participate in an interview in which they were asked to conduct a regular work situation (i.e., to catalog two items) and to document the process by thinking aloud. The protocols of their cataloging work were recorded.

\section{VERBAL REPORT EXERCISE}

A second form of protocol analysis was also given to those expert catalogers who preferred not to be interviewed. They were asked to complete a self-administered verbal report exercise. Each cataloger was given specific instructions and asked to catalog a typical item. The cataloger submitted a verbal report detailing the step-by-step process of problem solving and decision making in the cataloging case.

\section{VOLUNTARY PARTICIPATION}

Because of the obtrusive nature of the research method and the large amount of time involved, participants were selected for the project on a voluntary basis. A letter was sent to every cataloger with professional rank (GS-11 or above) in 41 cataloging teams (reaching a total of 367 professional catalogers) asking for volunteers to participate in protocol analysis. Fifty-eight positive responses (15.8\%) were received. Twenty-one protocol interview sessions were conducted, and 24 verbal reports were received from catalogers who participated in a self-administered verbal report exercise. Seventy-three bibliographic records and 49 authority records were created or modified during this project.

Content analysis was the primary method used in analyzing the data collected. The emphasis of data analysis was on (a) finding the general strategies used by expert catalogers so as to identify the mental models used during the process, (b) problem identification, and (c) discovering other issues encountered by the expert catalogers in the cataloging process. The rest of this paper demonstrates how verbal reports were used to collect information on cataloging tasks and presents some preliminary findings of the project.

\section{What's In Verbal Reports}

Two verbal reports are given here to exemplify the use of verbal reports and how they can provide a glimpse into the mental processes of experts. They capture a typical amount of complexity encountered by expert catalogers in the course of this study. For the purpose of this paper, the first cataloger is assigned the random numerical code 165 and is described as female, while the second is assigned 606 and described as male.

\section{ANALYSIS OF A SELF-ADMINISTERED VERBAL REPORT}

The first verbal report by Expert 165 was conducted as a self-administered verbal report that describes the steps involved in the process of descriptive cataloging for one item (the coded original report is given in figure 1). What story does this verbal report tell? For one thing, Expert 165 is a descriptive cataloger who performs only descriptive cataloging on her job. The verbal report itself does not describe the context in which the protocol occurred. However, observations of the routine process of descriptive cataloging at LC during this project helped the author establish the setting for this case. As in most cataloging settings at LC, Expert 165 chooses a book with the anticipation of finding not only the book but also a printout of the preliminary descriptive 
(1) Any special information on slips stuck in book?

(2) No

(3) Is a personal author metioned somewhere

(4) (Not on t.p.)

(5) No

(6) Title on cover

(7) but no note,

(8) as not different proper.

(9) Ned. Economics Research Group established?

(10) Yes

(11) What is "conducted for: master report"?

(12) Leave as is

(13) Make a.e. for "contemporary pediatrics"?

(14) (a serial)

(15) Yes

(16) Begin on-line work,

(17) working from top of screen to bottom

(18) Add code \& date to 955

(19) Proofread 245

(20) nothing to add or change

(21) 260

(22) 300 doublecheck "leaves,"

(23) not "pages"

(24) no no. prelim. p.

(25) Add a.e.s

(26) Look at Fixed fields,

(27) checking esp. boxes 20, 21, 23

(28) Big Question.

(29) Is there one big title or title plus subtitle?

(30) I decide to leave as is \& choose latter.

Figure 1. Coded Original Script of Verbal Report by Expert 165

cataloging record created by a preliminary cataloger in another division, and possibly a slip indicating any problems the preliminary cataloger has identified but is not authorized to solve. The expert works at a computer workstation with all the necessary descriptive cataloging tools, such as the Anglo-American Cataloguing Rules, second edition (AACR2) and LC's Descriptive Cataloging Manuals. These are standard tools on each cataloger's desk and are consulted by the cataloger when specific questions arise.

Expert 165 began her work on this book by checking whether the preliminary cataloger indicated any problem that needed her attention before she proceeded; this is typically noted on a special slip stuck in the book. Not finding any such slip, she proceeded to examine the title page. The question in Step 3 was very likely triggered by the potential application of AACR2 rule 21.1B1, 21.4A and $21.4 \mathrm{~B}$, in which the cataloger is to determine if there is a corporate body involved on the title page. The action, in turn, is probably triggered by her noticing a corporate body on the title page, although this was not documented in the verbal report. The answer in Step 4 shows that she did not find a personal name on the title page. This answer in Step 4 triggered the decision made in Step 8.

Instead of continuing the process of establishing the Statement of Responsibilities, Expert 165 at this point decided to keep her attention on the bibliographic data on the title page. She compared the title on the cover with that on the title page. She immediately decided that there 
was no need to create a note. This was based on the AACR2 rules governing use of notes to indicate a different cover title if one exists; Step 8 gives an explanation of AACR2, rule 2.7B4. Step 9 indicates another decision point triggered by LC's policy of establishing an authority record in the LC authority file for each corporate body encountered. A search into the LC Name Authority File (LCNAF) was conducted before the decision in Step 10 could be made, although the search was not reported in this verbal report.

Step 11 indicates that the expert continued her examination of the title page, as she found some special problems. Two problems were identified. One is the phrase "conducted for master report" on the title page. The other is another phrase "contemporary pediatrics" in Step 13. It is unclear from the self-administered verbal report what the cataloger did between Steps 11 and 12 that led her to the decision of Step 12. Nor is it clear what suggested to her the possibility that the phrase "contemporary pediatrics" could indicate a serial, as noted in Step 14 and her answer in Step 15 that the phrase is a serial title related to the book, therefore requiring an added entry.

Up to Step 15, Expert 165 concentrated her attention on the item at hand and the printout of the preliminary descriptive cataloging record. A step not recorded in this verbal report between Steps 15 and 16 is the process of retrieving the preliminary record for this book from the Multiple-Use MARC System (MUMS) catalog for editing. Beginning with Step 16 (i.e., once the record is located and displayed on screen), the cataloger turned her attention to the online screen. Step 17 describes the workflow that follows the screen display. Step 18 results from the LC's internal administrative routine, which requires all catalogers to identify themselves and date each record in Field 955 as an integral part of the process. Most catalogers do so as the initial step when they create or edit a record on screen.

Because Expert 165 worked on an existing record, the main process was proofreading bibliographic data in fields, as in- dicated in Step 19. The word leaves in field 300 caught her eye in Step 22 because it is a term that deviates from the common pagination method, as indicated in the explanation in Step 23. Preliminary pages present a problem in many descriptive cataloging cases, thus warranting special attention in Step 24. Once Expert 165 finished adding the added entry for the serial title, she had completed bibliographic description in all variable fields of the record. She then turned her attention to fixed fields (Step 26) and as most descriptive catalogers do at LC, checked especially fixed-field boxes 20,21 , and 23 for publication date, language, and geographic code.

One would think that Step 27 completed the process of descriptive cataloging. But in this case, Expert 165 went back to the item and identified another problem that was not indicated earlier in the verbal report: How to interpret the title? The question at hand was whether the book has a long title or a main title with a subtitle. Expert 165 did not consult the tools or rules, nor was there any evidence that a colleague was consulted. Although AACR2 rule 1.1B group deals with the transcription of title proper, no such rule is applicable in this circumstance, nor does any textbook exist that addresses the interpretation of bibliographic data on title pages. Catalogers must, as Hagler (1991) suggests, rely on their own bibliographic judgment in similar cases. This is evident in the decision made in Step 30, where the expert must use her judgment in interpreting the title. Although the expert first paid attention to the title in Step 6, the question of judgment and interpretation (i.e., main versus subtitle) was not raised until Step 29.

Was the problem of main versus subtitle discovered upon completing the work of descriptive cataloging? Or was the problem identified during the title examination in Step 6 and simply stayed in the cataloger's mind until all other, less tricky details were taken care of in the record? The answer is not apparent from the self-administered verbal report. 
1. Check if it is duplicate

2. edit Field 260 (publication and distribution, etc area) and fixed field information [no 300 for cip rec.]

3. back to 245 (title and statement of responsiblities area), wonder out loud about the subject

4. fill in 100 (main entry, personal names) without checking the name authority file

3. fill in a note in Field 504

6. browse the table of contents and other preliminaries

7. fill in Field 020 (ISBN), check the validity of ISBN

8. check Subject Cataloging Manual for theological heading

9. check name authority file for 100 heading [ok?]

10. browse other works by the author

11. check other works with title "English enlightenment", consult 650 of some of the records

12. read summary, comparing 650 (subject headings) headings with summary,

13. browse table of contents and the list of illustrations

14. read acknowledgement to see if other thinkers are involved

15. decide to drop "Heaven and hell" as a subject heading, and adopt the two from the other heading

16. add fixed information for Field 043 (geographic code)

17. add two more subject headings for England-Intellectual life

18. search the LC online catalog, MUMS by subject heading using the command: find afterlife

19. search for subject authority record for the heading: Future life

20. read all the headings and notes in $4 x x$ and $5 x x$

21. note the class number "BT899 or so"

22. find s Future doctrines; use $\mathrm{f}=$ bo command to limit the search to books

23. browse the list, display a few records and their subject headings, thinking about "Christianity" as a subdivision

24. find s enlightenment. consult subject authority record, sh85-44032

25. nccs. Delete the 2 SHs for England-Intellectual life. Change them to Enlightenment-England

26. correct a subfield code in Field 650 (subject heading)

27. browse the summary again

28. recall the record using "nccs" command and read the screen

29. check the index of classification schedule, BT, for Future state. Future life.

30. look at the page for BT899

31. use General works. 1951-. pcrd to proofread

Figure 2. Coded Script of the Verbal Report by Expert 606

\section{ANALYSIS OF A THINK-ALOUd Protocol}

The second verbal report represents a typical case of a protocol interview in which the expert cataloger was asked to catalog an item while thinking aloud along the process. (See figure 2 for summary notes of the think-aloud protocol). Expert 606 is a whole-book cataloger who has been trained to conduct both descriptive and subject cataloging of the same item under LC's whole-book cataloging project, which started in early 1990 s. As the protocol interview began, the cataloger spent some time explaining his strength in descriptive cataloging from his many years of experience and that he had only in recent years been involved in subject cataloging. Because of his background and recent changes in the whole-book cataloging policy on the job, he tended to approach cataloging with special attention 
on subject analysis, a new focus of learning for him.

As with the analysis of the first verbal report above, some information about the cataloging setting is in order before the analysis of this verbal report begins. In this case, Expert 606 was conducting both description and summarization with the purpose of creating a cataloging-in-publication (CIP) record for a galley proof submitted by a publisher who intended to use the CIP record upon printing of this book. The galley proof included all preliminary pages and the beginning chapter of the book. The interview took place in a cubicle containing cataloging workstation. Expert 606 had the galley proof pages and the copyright registration sheets submitted along with the galley proof by the publisher. Unlike in the previous case, no preliminary record for this item existed prior to the interview.

The first steps Expert 606 took were to determine whether this item fell into the subject scope of the cataloging team-i.e., religion, psychology and philosophy-and whether it was a duplicate. Once those two administrative questions were answered, the cataloger called up an empty workform on the screen and began to input bibliographic data into field 260 (publication, distribution, etc.) and related fixed field boxes. He indicated that there would be no field 300 (physical description) since this would be a CIP record. Once bibliographic data related to publisher and publication were completed on the screen workform, the cataloger turned his attention to field 100 (main entry, personal name) and filled in the author's name according to his knowledge of AACR2 chapter 24 . He did not check the name in the LC Name Authority File first. Data for the bibliographic note in field 504 were provided as the next step. Upon finishing that, Expert 606 browsed the table of contents and the preliminary pages to see what the book was about. In doing so, he encountered the ISBN number and immediately filled in the ISBN data in field 020 and checked its validity.

As Expert 606 browsed the table of contents and added some possible subject headings to 650 fields (subject headlings) for this item, he checked LC's Subject Cataloging Manual for theological headings. Not finding anything particular, he searched the personal name in the LCNAF to verify the form of heading in field 100. To do so, he switched to the MUMS cataloging system, searched the author's name, and found some of the author's works with the phrase "English enlightenment" either in the titles or in the subject headings. He proceeded with a title search using the phrase and consulted the headings in the 650 fields of those items found in this search.

Not satisfied with the subject headings he had on his workform, Expert 606 returned to the item in hand. He read the the summary provided by the publisher on the copyright registration sheets and considered some of the headings found in the above title search. At this point, the cataloger browsed the table of contents again and read through the list of illustrations. He also read the acknowledgments to see if names of other thinkers were mentioned. Upon doing so, he decided to drop one heading and added two other headings. A quick switch from subject cataloging to descriptive cataloging and back to subject cataloging occurred when Expert 606 added the fixed information for field 043 (geographic code). Upon returning to subject cataloging work, he added two more subject headings related to "England-Intellectual life." He then searched the MUMS catalog for the subject heading "Afterlife," and also searched LC's Subject Authority File for "Future life" and read all the headings and notes in Fields $4 \mathrm{XX}$ and $5 \mathrm{XX}$. As he did that, he noted the class number to be "BT899" and recorded it in field 050 (LC call number) of his workform.

The cataloger further searched other items with the subject heading "Future doctrines," browsed the resulting list, and displayed a few records. As a result of this browsing, the cataloger began to consider adding "Christianity" as a subdivision to the subject heading. Another subject search was conducted to find the subject authority record for the heading "Enlight- 
enment." Upon finishing reading the subject authority record, the Expert modified the subject headings he established earlier on the screen workform by deleting the two subject headings for "EnglandIntellectual life," changing them to "Enlightenment-England." $\mathrm{He}$ also corrected a subfield code in one of the $650 \mathrm{~s}$ he had used earlier and browsed the summary of the copyright registration sheets again.

At this point, Expert 606 read the entire workform one more time and was satisfied with what he saw. He then turned his attention to assigning the classification number. He checked the classification schedule BT under the index for "Future state. Future life," looked at the page for BT899, and finally decided to use "General works, 1951-." Classification work done, Expert 606 saved the record and called it up again on the screen to proofread it.

\section{Mental Processes}

The above description of the two verbal reports collected in this project at LC raises the question, What do the verbal reports tell us about the mental processes of experts involved in the cataloging process? Before answering this question, one should begin by noting that the two expert catalogers reported here have very different mental models even though they both conduct descriptive cataloging at the same institution under the same cataloging policy guidelines.

\section{General Strategies}

In terms of general strategies, Expert 165 exemplifies the common understanding of the cataloging process among educators and practitioners in the field. Her cataloging process follows the typical flow of working on a workform (in this case the printout provided by the preliminary cataloger) in a top-down manner beginning with main entry. Initially she spent time interpreting the item's bibliographic data, then moved on to the development of a draft record on the printout before she finally went to the computer to actually edit the screen workform. The workflow of Expert 165 largely begins with determination of access points, moving on to authority work, providing description, and finally editing the record.

Expert 606 , on the other hand, concentrated on the task of subject analysis throughout his protocol (which he believed was not his strength) and completed the routine tasks (such as filling out the descriptive fields) along the way. In many cases, the bibliographic data he recorded in the descriptive fields were used to a great extent in his research work for subject analysis for the item. While no defining workflow appears in his cataloging process, there was a clear, consistent theme to his cataloging process: subject analysis, with every other cataloging task for the item fit in around the theme. In comparison with Expert 165, Expert 606's descriptive cataloging workflow largely begins with providing description (ISBD area 4 , publication and distribution, etc., area) before moving on to determining access points. For Expert 606, unlike Expert 165 , creating and editing the screen workform is an ongoing process, not a separate step at the end.

\section{Problem Solving}

To a certain degree, the two expert catalogers are similar in their approaches to problem solving. Both experts ruled out problems of an administrative nature such as whether a specific book falls into the scope of their team) early in the process, but when it comes to problems of a substantial nature (such as interpretation of bibliographic data or matching the scope of subject headings with the topical themes of the item), the two experts differ. Expert 165 noted the problem of interpreting potential components of the title at the end of the session only after all other tasks were completed, and appeared reluctant to make personal judgements during the process without giving herself time to think or to consult with others. This strategy, although it kept the expert free from distraction in the process, does carry the risk that she might simply forget to make a decision on this item. Taking a 
different approach, Expert 606 made the special problem the central theme of his process and tried several alternative methods to reach his own satisfactory conclusions. Even when confronted with the need to verify the name authority form for the personal author, Expert 606 simply filled in Field 100 with what he considered to be the correct form of heading and only later returned to verify the form in the LCNAF.

\section{The Role of THE SCREen Workform}

One particularly interesting aspect in analyzing the verbal reports of the two experts is the way in which they use the cataloging workform on the computer screen. A screen workform is an empty or incomplete cataloging record with necessary MARC tags into which bibliographic data are added and edited to create a cataloging record for an item. The workform is the basis of the end-product in the cataloging process. Calling up the screen workform for the item at hand after she had verified all routine bibliographic data needed for description, Expert 165 appeared to treat the workform as something much closer to what one might call the end-product. Her verbal report suggests a formality to her process in which enough preparation must be done before proceeding with dealing with the screen workform.

This is absolutely not the case for Expert 606 , who called up a new workform the moment he sat down with the item and began filling in bibliographic data without much preparation. In many cases, the data in descriptive fields appeared incomplete or unverified until he went back a second time. Potential subject headings for the item were recorded into 650 fields as they were discovered at various times of the protocol interview, only to be deleted or modified later. The screen workform appeared to serve the same function as a blackboard on which he sketched out the blueprint of the cataloging record and changed his sketches as his thinking evolved. The screen workform did not become the actual end-product of a biblio- graphic record until he saved it and called it up again for proofreading.

\section{Potential Hypotheses}

Based on the forgoing discussion, I offer some hypotheses on the mental processes and the expertise of catalogers.

The first is related to the cataloging record. Some expert catalogers apparently follow the traditional concept that a cataloging record is regarded as the endproduct of the cataloging process and therefore tend to formalize the steps of creating and editing cataloging records only after a certain level of preparation is done. Other expert catalogers view a cataloging record as a workspace that can be used to draft their ideas and store their work progress; they consider the data in the record to be subject to constant change without any fear of losing the integrity of the cataloging record. One would think that the latter type of expert might be more open to changing bibliographic records even after they reach users.

Two issues related to this require further investigation. One is whether expert catalogers favor one model over the other. The other concerns the implications this hypothesis has on the common institutional practice among many cataloging systems regarding whether and how an error found in an existing record is corrected and who is authorized to do the correction.

The second hypothesis has to do with the free use of association to build one's own cataloging expertise, as seen in the second verbal report. Since Expert 606 perceived subject analysis as not one of his strengths (even though he possessed a few years of experience in it and might be considered an expert in that area by many people), he took the liberty of using whatever bibliographic data he could find to research the appropriateness of subject headings and to improve the degree of scope-match between the subject headings and the topical themes of the item. Data he used in networking and association in his protocol included (a) the author's name, (b) the author's other works, (c) other scholars' names associ- 
ated with the author by virtue of their appearance in the acknowledgment, and (d) works that share similar topical terms, among others. This networking and association strategy has proven to be a very powerful tool for learning and self-improvement in cataloging.

The third hypothesis offered here is based on the observations in both verbal reports suggesting that certain cataloging tools were not utilized in the experts' cataloging process as often as one would think. Expert 165, for example, appeared so confident in her knowledge of rules and tools that the use of rules and tools was never mentioned in her verbal report. Even when she noted the special problem of interpreting parts of the title at the end of her report, she made no attempt to check rules or local policy documentation to see if anything could help her decision. The only tool she used during the process was the Name Authority File. Expert 606, on the other hand, make extensive use of tools, including the Name Authority File, Subject Authority File, MUMS catalog, and the Subject Cataloging Manual. This leads to a possible hypothesis that cataloging tools are really of two kinds-the formal tools, such as AACR2 and Library of Congress Classification systems, and the contextual tools, which are specific to the cataloging end-products within a particular institution-and that the formal tools are used primarily for training, and the contextual primarily for local practice.

\section{Conclusion}

This paper demonstrates that the use of verbal reports is a valuable technique in in-depth studies on the quality of cataloging expertise. As many researchers and practitioners alike struggle to teach cataloging, to explain its professionalism, to train new catalogers, and to improve their own acquisition of cataloging knowledge and skills, the analysis of verbal reports, such as done here, can provide critical insights into the general strategies, mental models, and problem-solving skills of cataloging. Further analysis of the data gathered should offer specific proofs to test the three hypotheses described above and better understanding of the mental processes and expertise in cataloging.

\section{Works CITED}

Abrera, J., and D. Shaw. 1992. Frequency of use of cataloguing rules in a practice collection. Library resources \& technical services 36: 149-61.

Akin, O. 1980. Models of architectural knowledge. London, Pion.

Association for Library Collections and Technical Services. Committee on Education, Training, and Recruitment for Cataloging. 1994. Essential elements of training program for entry-level professional catalogers. ALCTS newsletter 5: 32-34.

Avram, Henriette D. 1989. Developing catalogers for the nation: Problems and issues in training cataloging librarians for the future. In Recruiting, educating, and training cataloging librarians, ed. Sheila S. Intner and Janet Swan Hill. New York: Greenwood.

Belkin, N. J., and H. M. Brooks. 1987. Knowledge elicitation using discourse analysis. International journal of man-machine studies 27: 127-44.

Benner, P. 1984. From novice to experts: Excellence and power in clinical nursing practice. Menlo Park, Calif.: AddisonWesley.

Chan, L. M. 1989. Inter-indexer consistency in subject cataloging. Information technology and libraries 8: 349-58.

Charness, N. 1976. Memory for chess positions: Resistance to interference. Journal of experimental psychology: Human learning and memory 2: 641-53.

Chase, W. G., and H. A. Simon. 1973. Perception in chess. Cognitive psychology 4: 55-81.

Cooper, M. D. 1991. User skill acquisition in office information systems. Journal of the American Society for Information Science 42: 735-46.

Cutter, Charles A. 1904. Rules for a dictionary catalog. 4th ed. Washington, D.C.: Govt. Print. Off.

Davies, R., and B. James. 1984. Toward an expert system for cataloguing: Some experiments based on AACR2, Program, 18: 283-97.

Davies, R. 1992. Expert systems and cataloging. In The application of expert systems in libraries and information centres, ed. A. Morris. London: Bowker-Saur, 133-66.

Egan, D. E., and B. J. Schwartz. 1979. Chunking in recall of symbolic drawings. Memory and cognition 7: 149-58. 
Elmes, D. G., and R. A. Bkork. 1975. The interaction of encoding and rehearsal processes in the recall of repeated and nonrepeated items. Journal of verbal learning and verbal behavior 14: 3042.

Ercegovac, Z. 1984. Knowledge-based expert systems: A profile and implications. In Proceedings of the Fifth National Online Meeting. Medford, N J : Learned Information, 1984, 39-46.

- 1992. A multiple-observation approach in knowledge acquisition for expert systems. Journal of American Society for Information Science 43: 506-17.

Ercegovac, Z., and H. Borko. 1992. Design and implementation of an experimental cataloguing advisor: Mapper. Information processing and management 28:241-57.

Ericsson, K. A., and H. A. Simon. 1984. Protocol analysis: Verbal reports as data. Cambridge, Mass.: MIT Pr.

Fenly, R. 1990. Expert systems and technical services. In Artificial intelligence and expert systems: Will they change the library?, ed. F. W. Lancaster and Linda C. Smith. Paper presented at the 1990 Clinic on Library Applications of Data Processing, March 25-27, 1990. Urbana: Graduate School of Library and Information Science, University of Illinois at UrbanaChampaign.

Fitzgerald, Michael. 1989. Training the cataloger: The Harvard experience. In Recruiting, educating, and training cataloging $l i-$ brarians, ed. Sheila S. Intner and Janet Swan Hill. New York: Greenwood, 301-12.

Giral, A., and A. G. Taylor. 1993. Indexing overlap and consistency between the Avery Index to Architectural Periodicals and the Architectural Periodicals Index. Library resources \& technical services 37 : 19-44.

Hagler, R. 1991. The bibliographic record and information technology. $2 \mathrm{~d}$ ed. Chicago: ALA.

Hjerppe, R., and B. Olander. 1989. Cataloging and expert systems: AACR2 as a knowledge base. Journal of the American Society for Information Science 40: 27-44.

Hjerppe, R., B. Olander, and K. Marklund. 1985. Project ESSCAPE-Expert Systems for Simple Choice of Access Points for Entries. In IFLA 51st General Conference. Linkoping: Linkoping University.

Hoffman, R. R. 1989. A survey of methods for eliciting the knowledge of experts. ACM SIGART Newsletter 108: 19-27.

Jeng, L. H. 1992. The conceptual obstacles to building the knowledge base for cataloging expert systems. In Proceedings of the Third LITA National Conference September 13-16, 1992, Denver, Colorado, ed. Thomas W. Leonhardt. Chicago: ALA, 6769.

1993. From cataloging to organization of information: A new paradigm for the core curriculum. Joumal of education for library and information science 34: 11326.

Jeng, L. H., and K. Weiss. 1994. Modeling cataloging expertise: A feasibility study. Information processing and management 29 : 119-29.

Johnson, P. E., and others. 1981. Expertise and error in diagnostic reasoning. Cognitive science 5: 235-83.

Johnson, P. E., I. Zaulkernam, and S. Garber. 1988. Specification of expertise. In Knowledge acquisition for knowledge-based systems, ed. B. R. Gaines and J. H. Boose. London, Academic, 125-45.

Kautto, Vesa. 1992. Classing and indexing: A comparative time study. International classification 19: 205-9.

Kolodner, J. L. 1983. Towards an understanding of the role of experience in the evolution from novice to expert. International journal of man-machine studies 19 : 497-518.

LaFrance, M. 1989. The quality of expertise: Implications of expert-novice differences for knowledge acquisition. ACM SIGART newsletter 108: 6-14.

Line, M. B. 1969. The cost of classification: A note. Cataloguing and indexing 16: 4.

Malinconico, S. Michael. 1974. The role of a machine based authority file in an automated bibliographic system. In Automation in libraries: Papers presented at the CACUL Workshop on Library Automation, Winnipeg, June 22-23, 1974. Ottawa: Canadian Library Association.

Markey, K. 1984. Interindexer consistency tests: A literature review and report of a test of consistency in indexing visual materials. Library and information science research 6: 155-77.

Martin, J. D., and M. Redmond. 1989. Acquiring knowledge by explaining observed problem solving. ACM SIGART Newsletter 108: 77-83.

Meador, R., and G. R. Wittig. 1991. AACR2 rules used in assigning access points for books in two subjects: Implications for automatic cataloguing expert systems. $\mathrm{Li}$ brary resources \& technical services 35 : 135-40. 
Norris, S. P. 1990. Effect of eliciting verbal reports of thinking on critical thinking test performance. Journal of educational measurement 27: 41-58.

Reynolds, R. 1975. Literature survey on time and cost data for classification and indexing. March 1973. In British Library Working Party on classification and indexing. London: British Library.

Richardson, J. V. 1995. Knowledge-based systems for general reference work: Applications, problems, and progress. San Diego: Academic.

Rowland, G. 1992. What do instructional designers actually do? An initial investigation of expert practice. Performance improvement quarterly 5: 65-86.

Saiz, M., and A. Breuleux. 1992. Planning as a function of expertise and task difficulty in a technical domain. Report. Available through ERIC Clearing House, ED346153.

Saracevic, T. 1989. Modeling and measuring user-intermediary-computer interaction in online searching: design of a study. In ASIS 89: Managing information and tech- nology. Proceedings of the 52nd Annual Meeting of the American Society for Information Science, Washington, D.C., 30 October-2 November 1989, 26, 75-80.

Schael, J., and J. Dionne. 1991. Judges' agreement and disagreement patterns when encoding verbal protocols. Paper presented at the Annual Meeting of the American Educational Research Association, Chicago, April 1991.

Sievert, M. E. C.; M. J. Andrews. 1991. Indexing consistency in Information Science $\mathrm{Ab}$ stracts. Journal of the American Society for Information Science 42: 1-6.

Smagorinsky, P. 1991. The writer's knowledge and the writing process: a protocol analysis. Research in the teaching of English 25, no. 3: 339-64.

Thomas, P. 1993. The user interface of ERIC on the Macintosh: A qualitative study of novice users. Master's thesis. Kent State University, 1993.

Van Someren, M. W., Y. F. Barnard, and J. A. C. Sandberg. 1994. The think aloud method: A practical guide to modelling cognitive processes. London: Academic.

\section{STATEMENT OF OWNERSHIP AND MANAGEMENT}

Library Resources \& Technical Services is published quarterly (January, April, July, October) by the Association for Library Collections and Technical Services, American Library Association, $50 \mathrm{E}$. Huron St., Chicago, IL 60611-2795. Annual subscription price, \$20.00. American Library Association, owner; Richard P. Smiraglia, Editor, Palmer School of Library and Information Science, Long Island University, Brookville, NY 11548. Periodicals postage paid at Chicago, Illinois. Printed in U.S.A. As a nonprofit organization authorized to mail at special rates (Section 423.12, Domestic Mail Manual), the purpose, function, and nonprofit status of this organization and the exempt status for federal income tax purposes have not changed during the preceding twelve months.

\section{EXTENT AND NATURE OF CIRCULATION}

("Average" figures denote the average number of copies printed each issue during the preceding twelve months; "Actual" figures denote actual number of copies of single issue published nearest to filing date-the April 1996 issue.) Total number of copies printed: Average, 7,584; Actual, 7,863. Paid and/or requested circulation: not applicable (i.e., no sales through dealers and carriers, street vendors, and counter sales). Mail subscriptions: Average, 6,954; Actual, 7,170. Total paid and/or requested circulation: Average, 6,954; Actual, 7,170. Free distribution by mail, carrier or other means, samples, complimentary, and other free copies: Average, 79; Actual, 71. Total distribution: Average 7,033; Actual, 7,241, Copies not distributed: office use, left over, unaccounted, spoiled after printing: Average, 551 ; Actual 622. Retums from news agents: not applicable. Total (sum previous three eniries): Average, 7,$584 ;$ Actual, 7,863 . 